\title{
Article \\ Co-Toxicity Factor Analysis Reveals Numerous Plant Essential Oils Are Synergists of Natural Pyrethrins against Aedes aegypti Mosquitoes
}

\author{
Edmund J. Norris ${ }^{1,2, *(D)}$ and Jeffrey R. Bloomquist ${ }^{2}(\mathbb{D}$ \\ 1 United States Department of Agriculture, Center for Medical, Agricultural, and Veterinary Entomology, \\ Gainesville, FL 32610, USA \\ 2 Emerging Pathogens Institute, Entomology and Nematology Department, University of Florida, \\ Gainesville, FL 32610, USA; jbquist@epi.ufl.edu \\ * Correspondence: edmund.norris@usda.gov; Tel.: +1-(708)-363-3223
}

check for

updates

Citation: Norris, E.J.;

Bloomquist, J.R. Co-Toxicity Factor

Analysis Reveals Numerous Plant

Essential Oils Are Synergists of

Natural Pyrethrins against Aedes aegypti Mosquitoes. Insects 2021, 12, 154. https://doi.org/10.3390/ insects12020154

Academic Editor:

Antonios N. Michaelakis

Received: 11 January 2021

Accepted: 7 February 2021

Published: 11 February 2021

Publisher's Note: MDPI stays neutral with regard to jurisdictional claims in published maps and institutional affiliations.

Copyright: (c) 2021 by the authors. Licensee MDPI, Basel, Switzerland. This article is an open access article distributed under the terms and conditions of the Creative Commons Attribution (CC BY) license (https:/ / creativecommons.org/licenses/by/ $4.0 /)$.
Simple Summary: With insecticide-resistant mosquito populations becoming an ever-growing concern, new vector control technologies are needed. Plant essential oils represent new insecticides and repellents, which are generally safer to mammals and non-target organisms than conventional materials. A set of 20 plant essential oils was screened alone and in combination with a natural insecticide, pyrethrins, for their ability to produce immobilization (knockdown at $1 \mathrm{~h}$ ) and mortality at $24 \mathrm{~h}$ against the yellow fever mosquito. Overall, only a few of the oils produced considerable mortality or knockdown when applied alone at the doses used in this study. However, a number of them synergized or antagonized the toxicity of natural pyrethrins when applied in mixtures. These findings highlight select plant essential oils that may offer important avenues for the development of future insecticide synergists. Moreover, synergism or antagonism was highly dependent on the amount of the oil applied, e.g., some oils were more effective at improving natural pyrethrins toxicity at low doses, whereas others were better at improving its toxicity at high doses.

Abstract: With insecticide-resistant mosquito populations becoming an ever-growing concern, new vector control technologies are needed. With the lack of new chemical classes of insecticides to control mosquito populations, the development of novel synergists may improve the performance of available insecticides. We screened a set of 20 plant essential oils alone and in combination with natural pyrethrins against Aedes aegypti (Orlando) female adult mosquitoes to assess their ability to synergize this natural insecticide. A co-toxicity factor analysis was used to identify whether plant oils modulated the toxicity of natural pyrethrins antagonistically, additively, or synergistically. Both knockdown at $1 \mathrm{~h}$ and mortality at $24 \mathrm{~h}$ were monitored. A majority of oils increased the toxicity of natural pyrethrins, either via an additive or synergistic profile. Many oils produced synergism at $2 \mu \mathrm{g} /$ insect, whereas others were synergistic only at the higher dose of $10 \mu \mathrm{g} /$ insect. Amyris, cardamom, cedarwood, and nutmeg East Indies (E.I.) oils were the most active oils for increasing the mortality of natural pyrethrins at $24 \mathrm{~h}$ with co-toxicity factors greater than 50 at either or both doses. A number of oils also synergized the $1 \mathrm{~h}$ knockdown of natural pyrethrins. Of these, fir needle oil and cypress oils were the most successful at improving the speed-of-action of natural pyrethrins at both doses, with co-toxicity factors of 130 and 62, respectively. To further assess the co-toxicity factor method, we applied selected plant essential oils with variable doses of natural pyrethrins to calculate synergism ratios. Only the oils that produced synergistic co-toxicity factors produced statistically significant synergism ratios. This analysis demonstrated that the degree of co-toxicity factor correlated well with the degree of synergism ratio observed (Pearson correlation coefficient $\mathrm{r}=0.94$ at $2 \mu \mathrm{g}$ /insect; $\mathrm{r}=0.64$ at $10 \mu \mathrm{g} /$ insect) and that the co-toxicity factor is a useful tool in screening for synergistic activity.

Keywords: synergism; antagonism; knockdown; piperonyl butoxide; mosquito; yellow fever mosquito 


\section{Introduction}

Plant essential oils are now recognized as effective alternatives to synthetic insecticides against a wide variety of pests. Their generally pleasant aroma, relatively low toxicity to humans and pets, and perceived salubrious qualities have given rise to a large increase in research focused on the development of these agents for pest control [1]. The consumer market has also seen a shift from synthetic insecticides to natural ingredients, as many of these bioactive chemistries are either safer to humans and/or the environment, or perceived to be so [2-4]. However, despite the benefits of their use, it is erroneous to assume that all products containing plant essential oils and plant extracts act similarly. To truly appreciate their value, it is necessary to examine their toxic/repellent effects in order to identify the most efficacious chemistries that could be included in future arthropod control technologies [2].

Some components in essential oil-based insecticide formulations are considered "generally recognized as safe" (GRAS) by the United States Environmental Protection Agency, under the Federal Insecticide, Fungicide, and Rodenticide Act (FIFRA) [4]. These components are listed in the 25b Exempt category under FIFRA code due to their usage throughout human history, and because they are found in many household food items and fragrances $[4,5]$. Reclassification of certain components has relaxed the regulatory requirements for registration of plant essential oil-based insecticides and repellents, and allowed for the rapid diversification of novel products. Coupled with the recent consumer-driven push for more natural and "green" control strategies, more of these products are now available for purchase than ever before [3,5]. While not as potent as synthetic insecticides, their potential to kill and repel arthropods is appreciable [6-8]. Moreover, many oils have been shown to produce potent synergism with various synthetic insecticides, further demonstrating their utility. Gross et al. [9] demonstrated that various plant essential oils could enhance the toxicity of permethrin against adult female Aedes aegypti and Anopheles gambiae. Norris et al. [6] showed that the most successful plant oils in the Gross et al. 2015 study could synergize diverse type I and type II pyrethroids, further indicating their activity as synergists. It is important to continually identify novel synergists and toxic additives that could be combined with synthetic insecticides in future insecticidal formulations.

The goal of this study was to assess the ability of various plant essential oils to improve the toxicity of natural pyrethrins against Aedes aegypti of the insecticide-susceptible Orlando strain. For this, we acquired 20 plant essential oils and screened them alone and in combination with natural pyrethrins at discrete doses to characterize their potential to improve knockdown and lethality. To identify and quantify synergism produced by various plant essential oils, we utilized a co-toxicity factor method proposed by Mansour et al. [10]. After calculating the co-toxicity factor for various doses of plant essential oils applied in combination with natural pyrethrins, we calculated traditional synergism ratios for selected oils to evaluate the co-toxicity factor method as a diagnostic tool for the identification of novel synergists.

\section{Materials and Methods}

\subsection{Chemicals}

Plant essential oils were obtained from Berje, Inc. (Carteret, NJ, USA). Oils were selected for their novelty compared to what has been screened previously in the literature $[6,8,9,11-14]$. Natural pyrethrins were obtained from Fairfield American Corp. (Newark, NJ, USA). Pure ethanol (100\%) was used as a vehicle for plant oils and natural pyrethrins and was obtained from Sigma Aldrich (St. Louis, MO, USA). Piperonyl butoxide (PBO) $(>95 \%)$ was also obtained from Sigma Aldrich (St. Louis, MO). Sucrose for sugar water was obtained from Domino (Baltimore, MD, USA).

\subsection{Insects}

Orlando strain Aedes aegypti females were reared according to standard procedures utilized by the United States Department of Agriculture (USDA) [15]. Pupae were provided 
by the USDA prior to experiments. Pupae were allowed to eclose in $20.3 \times 20.3 \times 20.3 \mathrm{~cm}$ cages (Bioquip, Inc., Rancho Dominguez, CA, USA) and provided 10\% sucrose water ad libitum prior to experiments. Mosquitoes were kept in incubators (Darwin Chambers, St. Louis, MO, USA) maintained at $28{ }^{\circ} \mathrm{C} \pm 75 \%$ humidity with a $12: 12$ light dark cycle. Only non-blood-fed adult females were used for each experiment, and treated individuals ranged from 2-7 days old [16].

\subsection{Topical Application}

Topical applications of ethanolic solutions containing natural pyrethrins and/or essential oils were performed using methods similar to those outlined in [6]. Concentrations of natural pyrethrins ranged from those producing $10 \%$ to $90 \%$ mortality to ensure a good fit for probit models and to accurately calculate $\mathrm{LD}_{25}$ and $\mathrm{LD}_{50}$ values. Plant essential oils were applied at either $2 \mu \mathrm{g} /$ insect or $10 \mu \mathrm{g} /$ insect alone or in combination with the approximate $\mathrm{LD}_{25}$ of natural pyrethrins. The $\mathrm{LD}_{25}(1.6 \mathrm{ng} / \mathrm{mosquito})$ was calculated using a Probit model and given as a discrete dose assuming the weight of female mosquitoes was $2.85 \pm 0.08 \mathrm{mg} / \mathrm{mosquito}$ (average from five cohorts with SEM). Topical applications were performed by anesthetizing adult female mosquitoes on ice for $5 \mathrm{~min}$, and then placing them on a cold, glass Petri dish to prevent reanimation. A Whatman No. 2 filter paper was used to prevent mosquitoes from coming in contact with excess condensation. A $0.2 \mu \mathrm{L}$ volume of each treatment was applied to the pronotum of each mosquito using a Hamilton (Reno, NV, USA) repeating applicator with a gastight Hamilton syringe and placed in $470 \mathrm{~mL}$ deli paper cups. At least five concentrations were used to obtain $\mathrm{LD}_{25}$ and $\mathrm{LD}_{50}$ values for natural pyrethrins alone or in combination with select oils. Ten mosquitoes were treated for each concentration representing one replicate, and at least three different cohorts of mosquitoes were used for each concentration in an effort to control for biological variability in the mosquitoes produced by the Orlando colony. A cohort was defined as a distinct rearing group (i.e., adult mosquitoes obtained from distinct batches of eggs placed in water to initiate development each week). Controls were performed using the vehicle, ethanol. Tulle fabric, fastened to the cup with a deli cup lid rim (center removed), was used to keep mosquitoes from escaping. Deli cups containing ten treated mosquitoes per concentration per replicate were placed in an incubator for the remainder of the experimental interval and kept at the same temperature and light cycle as during rearing. Knockdown, defined as the inability to fly or maintain normal standing posture, was recorded at $1 \mathrm{~h}$, and mortality was recorded at $24 \mathrm{~h}$. Mortality was defined as no movement, even after gently tapping the cup several times to assess response.

\subsection{Data Analysis}

To assess synergism, the co-toxicity factor method was utilized [10]. In short, percentage knockdown and mortality was recorded for all treatments of plant essential oils alone, natural pyrethrins alone, and combinations thereof, and co-toxicity factors were calculated using the following equation:

$$
\text { Co }- \text { toxicity Factor }=\frac{\text { Observed Mortality }- \text { Expected Mortality }}{\text { Expected Mortality }} \times 100
$$

In this equation, observed mortality was the toxicity observed experimentally in combinations of plant oils and natural pyrethrins at either specific dose of plant essential oils ( 2 and $10 \mu \mathrm{g} /$ insect). Expected mortality was the additive sum of the observed mortality for natural pyrethrins alone and each plant essential oil alone. Values $>20$ represent synergistic mixtures, $-20 \leq$ values $\leq 20$ represent additive mixtures and values $<-20$ represent mixtures that are antagonistic. An $\mathrm{LD}_{25}$ of natural pyrethrins was used alone or in combination with discrete doses of plant essential oils to calculate co-toxicity values. $\mathrm{LD}_{50}$ and $\mathrm{LD}_{25}$ values for natural pyrethrins were derived from Probit analysis (Finney et al. 1952 [17]), using a PROC Probit calculation with a control correction option (OPTC) (to account for control 
mortality) performed in SAS 9.4 (SAS Institute, Inc., Cary, NC, USA). After synergistic combinations were identified using the co-toxicity factor method, conventional synergism ratios $\left(\mathrm{LD}_{50}\right.$ of natural pyrethrins alone $\div \mathrm{LD}_{50}$ of natural pyrethrins + a sublethal dose of essential oil) were calculated to evaluate the degree of synergism produced. These experiments were done for comparison and to further evaluate the performance of the cotoxicity factor method outlined by Mansour et al. 1966 [10]. To compare effects at discrete doses to one another or between those and control, an ANOVA $(\alpha=0.05)$ with a Tukey's post-test was used with an $\alpha$ value of 0.05 . For synergism assessments at discrete doses of plant essential oils, natural pyrethrins were applied in every cohort to obtain a relevant percentage mortality for the $\mathrm{LD}_{25}$ of natural pyrethrins for each cohort. As the response to natural pyrethrins differed slightly in every cohort, this approach ensured that cohort bias was accounted for in all comparisons in the analysis. As a result, the responses for natural pyrethrins alone and plant essential oils alone were adequately taken into account in the co-toxicity calculations for each combination of oil and natural pyrethrins using the aforementioned equation.

\section{Results}

Overall, plant essential oils exhibited a spectrum of activity when applied both alone and in combination with natural pyrethrins. Unique differences were observed in knockdown at $1 \mathrm{~h}$ and mortality at $24 \mathrm{~h}$ for each essential oil. At 2 (Table 1) and $10 \mu \mathrm{g} /$ insect (Table 2), a majority of oils did not produce any effects significantly different from the control when applied alone. Only balsam (Peru) produced significant knockdown at $2 \mu \mathrm{g} /$ insect compared to the control (Table 1), but the overall mean level of knockdown was low; $20 \pm 5.8 \%$ at $1 \mathrm{~h}$ (mean $\pm \mathrm{SEM}$ ). Moreover, at the $2 \mu \mathrm{g} /$ insect dose, no oils produced significant mortality compared to the control, but at $10 \mu \mathrm{g} /$ insect (Table 2), more plant essential oils caused significant knockdown and mortality compared to the ethanol control. Piperonyl butoxide (PBO), Amyris, balsam (Peru), cypress, and guaiacwood all produced significant $1 \mathrm{~h}$ knockdown, and among these, balsam (Peru) $(73.3 \pm 12 \%)$ produced the highest levels of $1 \mathrm{~h}$ knockdown at this screening concentration. Piperonyl butoxide (PBO), Amyris, Canadian balsam fir, citronella, and guaiacwood all produced statistically significant mortality compared to the ethanol control at $24 \mathrm{~h}$ when applied at $10 \mu \mathrm{g} /$ insect; however, only $\mathrm{PBO}$, Canadian balsam fir, and guaiacwood produced mortality that was greater than $50 \%$ (Table 2).

Table 1. Percentage $1 \mathrm{~h}$ knockdown and $24 \mathrm{~h}$ mortality values for natural pyrethrins $\left(\mathrm{LD}_{25}\right)$, plant essential oils or PBO synergists $(2 \mu \mathrm{g} /$ insect), mixture of natural pyrethrins + synergist, and the calculated co-toxicity factors for each mixture.

\begin{tabular}{|c|c|c|c|c|c|c|c|c|}
\hline \multirow{2}{*}{$\begin{array}{c}\text { Essential } \\
\text { Oil/Compound }\end{array}$} & \multicolumn{4}{|c|}{1 h \% Knockdown \pm SE } & \multicolumn{4}{|c|}{24 h \% Mortality \pm SE } \\
\hline & $\begin{array}{c}\text { Natural } \\
\text { Pyrethrins }\end{array}$ & Synergist & Mixture & $\begin{array}{l}\text { Co-toxicity } \\
\text { Factor }\end{array}$ & $\begin{array}{c}\text { Natural } \\
\text { Pyrethrins }\end{array}$ & Synergist & Mixture & $\begin{array}{c}\text { Co-Toxicity } \\
\text { Factor }\end{array}$ \\
\hline Control (ethanol) & NA & $0.6 \pm 0.6$ & NA & NA & NA & $1.8 \pm 1$ & NA & NA \\
\hline $\mathrm{PBO}$ & $46.7 \pm 3.7$ & $6.7 \pm 3.7$ & $10 \pm 3.7$ & -81.2 & $8.9 \pm 3.3$ & $6.7 \pm 2.4$ & $26.7 \pm 3.7$ & 71.2 \\
\hline Amyris & $48.5 \pm 5.1$ & $6.7 \pm 3.3$ & $63.3 \pm 21.9$ & 14.7 & $11.4 \pm 2.6$ & $3.3 \pm 3.3$ & $33.3 \pm 8.8$ & 127 \\
\hline Balsam Copaiba & $50 \pm 5.8$ & $2.5 \pm 2.5$ & $32.5 \pm 4.8$ & -38.1 & $13.8 \pm 3.7$ & $2.5 \pm 2.5$ & $25 \pm 2.9$ & 53.4 \\
\hline Balsam Peru & $58 \pm 8$ & $20 \pm 5.8 *$ & $60 \pm 10$ & -23 & $18 \pm 5.8$ & $10 \pm 10$ & $26.7 \pm 12$ & -4.6 \\
\hline Cade & $23.3 \pm 6.6$ & $6.6 \pm 6.6$ & $23.3 \pm 18.6$ & -22.1 & $6.6 \pm 3.3$ & $10 \pm 5.8$ & $3.3 \pm 3.3$ & -80.1 \\
\hline Canadian Balsam Fir & $40 \pm 5.8$ & $15 \pm 8.8$ & $20 \pm 0$ & -63.6 & $13.3 \pm 8.8$ & $20 \pm 0$ & $23.3 \pm 3.3$ & -21 \\
\hline Cardamom & $60 \pm 5.8$ & $0 \pm 0$ & $60 \pm 5.8$ & 0 & $20 \pm 10$ & $0 \pm 0$ & $10 \pm 10$ & -50 \\
\hline Cedarleaf & $58 \pm 8$ & $3.3 \pm 3.3$ & $56.7 \pm 3.3$ & -7.5 & $18 \pm 5.8$ & $13.3 \pm 8.8$ & $36.7 \pm 8.8$ & 17.3 \\
\hline Cedarwood Texas & $47.8 \pm 4.9$ & $4 \pm 2.4$ & $44 \pm 9.3$ & -15.1 & $14.4 \pm 5.3$ & $14 \pm 7.5$ & $50 \pm 8.9$ & 76.1 \\
\hline Cedarwood Virginian & $36 \pm 4$ & $0 \pm 0$ & $63.3 \pm 8.8$ & 75.8 & $18 \pm 9.2$ & $6 \pm 4$ & $30 \pm 7.1$ & 25 \\
\hline Citronella & $29 \pm 3$ & $1.3 \pm 1.3$ & $18.6 \pm 2.7$ & -39.2 & $29.3 \pm 2.8$ & $4 \pm 4$ & $29.3 \pm 3.5$ & -13.1 \\
\hline Cypress & $50 \pm 4.5$ & $5 \pm 5$ & $62.5 \pm 15.5$ & 13.6 & $13.3 \pm 2.1$ & $5 \pm 5$ & $12.5 \pm 6.3$ & -32.4 \\
\hline Dillseed & $26.7 \pm 3.3$ & $0 \pm 0$ & $40 \pm 17.3$ & 49.8 & $6.7 \pm 3.3$ & $3.3 \pm 3.3$ & $16.6 \pm 16.6$ & 66 \\
\hline
\end{tabular}


Table 1. Cont.

\begin{tabular}{|c|c|c|c|c|c|c|c|c|}
\hline \multirow{2}{*}{$\begin{array}{c}\text { Essential } \\
\text { Oil/Compound }\end{array}$} & \multicolumn{4}{|c|}{$1 \mathrm{~h} \%$ Knockdown $\pm \mathrm{SE}$} & \multicolumn{4}{|c|}{24 h $\%$ Mortality $\pm S E$} \\
\hline & $\begin{array}{c}\text { Natural } \\
\text { Pyrethrins }\end{array}$ & Synergist & Mixture & $\begin{array}{l}\text { Co-toxicity } \\
\text { Factor }\end{array}$ & $\begin{array}{c}\text { Natural } \\
\text { Pyrethrins }\end{array}$ & Synergist & Mixture & $\begin{array}{c}\text { Co-Toxicity } \\
\text { Factor }\end{array}$ \\
\hline Dillweed & $60 \pm 5.8$ & $6.7 \pm 3.3$ & $53.3 \pm 6.7$ & -20 & $20 \pm 10$ & $10 \pm 5.8$ & $16.7 \pm 3.3$ & -44.3 \\
\hline Fennel & $50 \pm 5.8$ & $2.5 \pm 2.5$ & $70 \pm 9.1$ & 33.3 & $13.8 \pm 3.7$ & $5 \pm 5$ & $25 \pm 15$ & 33 \\
\hline Fir Needle Oil & $30 \pm 5.8$ & $0 \pm 0$ & $53.3 \pm 18.6$ & 77.6 & $20 \pm 10$ & $3.3 \pm 3.3$ & $30 \pm 11.5$ & 28.8 \\
\hline Galbanum & $40 \pm 4.5$ & $2.5 \pm 2.5$ & $47.5 \pm 11.1$ & 11.8 & $12 \pm 7.3$ & $6 \pm 6$ & $4 \pm 4$ & -77.8 \\
\hline Ginger Root & $40 \pm 5.8$ & $0 \pm 0$ & $30 \pm 10$ & -25 & $13.3 \pm 8.8$ & $13.3 \pm 8.8$ & $13.3 \pm 6.6$ & -50 \\
\hline Guaiacwood & $30 \pm 0$ & $10 \pm 5.8$ & $36.7 \pm 13.3$ & -8.25 & $6.6 \pm 3.3$ & $10 \pm 5.8$ & $16.7 \pm 6.7$ & 0 \\
\hline Nutmeg EI & $47.1 \pm 5.2$ & $3.3 \pm 3.3$ & $53.3 \pm 6.6$ & 5.8 & $10 \pm 3.1$ & $0 \pm 0$ & $40 \pm 20$ & 300 \\
\hline Parsley & $60 \pm 5.8$ & $6.7 \pm 6.7$ & $83.3 \pm 6.6$ & 24.9 & $20 \pm 10$ & $13.3 \pm 3.3$ & $26.7 \pm 21.9$ & -19.8 \\
\hline
\end{tabular}

denotes statistically significant percentage from the control via ANOVA $(\alpha=0.05)$ with a Tukey's post-test; Bold numerals represent synergistic combinations; Red numerals represent antagonistic combinations.

Table 2. Percentage $1 \mathrm{~h}$ knockdown and $24 \mathrm{~h}$ mortality values for natural pyrethrins $\left(\mathrm{LD}_{25}\right)$, plant essential oils or piperonyl butoxide (PBO) synergists $(10 \mu \mathrm{g} /$ insect), mixture of natural pyrethrins + synergist, and the calculated co-toxicity factors for each mixture.

\begin{tabular}{|c|c|c|c|c|c|c|c|c|}
\hline \multirow{2}{*}{$\begin{array}{c}\text { Essential } \\
\text { Oil/Compound }\end{array}$} & \multicolumn{4}{|c|}{$1 \mathrm{~h} \%$ Knockdown $\pm \mathrm{SE}$} & \multicolumn{4}{|c|}{$24 \mathrm{~h} \%$ Mortality \pm SE } \\
\hline & $\begin{array}{c}\text { Natural } \\
\text { Pyrethrins }\end{array}$ & Synergist & Mixture & $\begin{array}{l}\text { Co-Toxicity } \\
\text { Factor }\end{array}$ & $\begin{array}{c}\text { Natural } \\
\text { Pyrethrins }\end{array}$ & Synergist & Mixture & $\begin{array}{c}\text { Co-Toxicity } \\
\text { Factor }\end{array}$ \\
\hline Control (ethanol) & NA & $0.6 \pm 0.6$ & NA & NA & NA & $1.8 \pm 1$ & NA & NA \\
\hline $\mathrm{PBO}$ & $46.7 \pm 3.7$ & $21.7 \pm 4^{*}$ & $21.7 \pm 4.5$ & -115 & $8.9 \pm 3.3$ & $65 \pm 8^{*}$ & $80 \pm 8.3$ & 8.2 \\
\hline Amyris & $48.5 \pm 5.1$ & $47.5 \pm 13.8 *$ & $57.5 \pm 13.1$ & -40 & $11.4 \pm 2.6$ & $35 \pm 16.6 *$ & $70 \pm 12.2$ & 50.8 \\
\hline Balsam Copaiba & $50 \pm 5.8$ & $5 \pm 2.9$ & $40 \pm 4.1$ & -27.3 & $13.8 \pm 3.7$ & $10 \pm 5.8$ & $30 \pm 26.3$ & 26.1 \\
\hline Balsam Peru & $58 \pm 8$ & $73.3 \pm 12 *$ & $76.7 \pm 14.5$ & -41.6 & $18 \pm 5.8$ & $26.7 \pm 8.8$ & $43.3 \pm 8.8$ & -9.2 \\
\hline Cade & $23.3 \pm 6.6$ & $23.3 \pm 13.3$ & $56.7 \pm 23.3$ & 21.7 & $6.6 \pm 3.3$ & $26.7 \pm 12$ & $30 \pm 11.5$ & -9.9 \\
\hline Canadian Balsam Fir & $40 \pm 5.8$ & $25 \pm 5$ & $30 \pm 10$ & -53.8 & $13.3 \pm 8.8$ & $70 \pm 11.5 *$ & $60 \pm 10$ & -28 \\
\hline Cardamom & $60 \pm 5.8$ & $0 \pm 0$ & $83.3 \pm 8.8$ & 38.8 & $20 \pm 10$ & $0 \pm 0$ & $40 \pm 17.3$ & 200 \\
\hline Cedarleaf & $58 \pm 8$ & $6.7 \pm 3.3$ & $73.3 \pm 6.6$ & 13.3 & $18 \pm 5.8$ & $6.7 \pm 3.3$ & $50 \pm 11.5$ & 102 \\
\hline Cedarwood Texas & $47.8 \pm 4.9$ & $8.3 \pm 3.1$ & $40 \pm 6.8$ & -28.7 & $14.4 \pm 5.3$ & $23.3 \pm 10.5$ & $55 \pm 14.3$ & 45.9 \\
\hline Cedarwood Virginian & $36 \pm 4$ & $6.7 \pm 3.3$ & $66.7 \pm 8.8$ & 56.2 & $18 \pm 9.2$ & $18 \pm 8.6$ & $54 \pm 12.9$ & 50 \\
\hline Citronella & $29 \pm 3$ & $4 \pm 0$ & $20 \pm 4.6$ & -39.4 & $22 \pm 7.2$ & $37.3 \pm 6.1 *$ & $47.5 \pm 6.3$ & -19.9 \\
\hline Cypress & $50 \pm 4.5$ & $10 \pm 0 *$ & $97.5 \pm 2.5$ & 62.5 & $13.3 \pm 2.1$ & $5 \pm 2.9$ & $22.5 \pm 6.3$ & 21.6 \\
\hline Dillseed & $26.7 \pm 3.3$ & $23.3 \pm 3.3$ & $43.3 \pm 18.6$ & -13.4 & $6.7 \pm 3.3$ & $13.3 \pm 6.6$ & $26.7 \pm 8.8$ & 33.5 \\
\hline Dillweed & $60 \pm 5.8$ & $0 \pm 0$ & $76.7 \pm 8.8$ & 27.8 & $20 \pm 10$ & $0 \pm 0$ & $33.3 \pm 6.7$ & 66.5 \\
\hline Fennel & $50 \pm 5.8$ & $10 \pm 4.1$ & $52.5 \pm 2.5$ & -12.5 & $13.8 \pm 3.7$ & $7.5 \pm 2.5$ & $30 \pm 9.1$ & 40.8 \\
\hline Fir Needle Oil & $30 \pm 5.8$ & $3.3 \pm 3.3$ & $76.6 \pm 8.8$ & 130 & $20 \pm 10$ & $6.6 \pm 6.6$ & $30 \pm 5.8$ & 12.7 \\
\hline Galbanum & $40 \pm 4.5$ & $7.5 \pm 7.5$ & $35 \pm 14.4$ & -26.3 & $12 \pm 7.3$ & $12 \pm 12$ & $10 \pm 5.5$ & -58.3 \\
\hline Ginger Root & $40 \pm 5.8$ & $10 \pm 10$ & $45 \pm 5$ & -10 & $13.3 \pm 8.8$ & $6.6 \pm 3.3$ & $33.3 \pm 3.3$ & 67.3 \\
\hline Guaiacwood & $30 \pm 0$ & $43.3 \pm 13.3 *$ & $56.7 \pm 12$ & 22.6 & $6.6 \pm 3.3$ & $66.7 \pm 8.8^{*}$ & $66.7 \pm 8.8$ & -9 \\
\hline Nutmeg EI & $47.1 \pm 5.2$ & $7.5 \pm 4.8$ & $57.5 \pm 6.3$ & 5.3 & $10 \pm 3.1$ & $2.5 \pm 2.5$ & $\begin{array}{c}27.5 \pm \\
12.5\end{array}$ & 120 \\
\hline Parsley & $60 \pm 5.8$ & $23.3 \pm 12$ & $83.3 \pm 8.8$ & 0 & $20 \pm 10$ & $3.3 \pm 3.3$ & $46.7 \pm 12$ & 100 \\
\hline
\end{tabular}

* denotes statistically significant percentage from the control via ANOVA $(\alpha=0.05)$ with a Tukey's post-test; Bold numerals represent synergistic combinations; Red numerals represent antagonistic combinations.

In order to screen for synergistic interactions between natural pyrethrins and plant essential oils, they were applied with a calculated $\mathrm{LD}_{25}$ of natural pyrethrins. The theoretical $\mathrm{LD}_{25}$ and $\mathrm{LD}_{50}$ for natural pyrethrins were calculated to be $0.55 \mathrm{ng} / \mathrm{mg}$ insect and $1.53 \mathrm{ng} / \mathrm{mg}$ insect, respectively. As the weight for each mosquito cohort varied, we applied a discrete dose (1.6 ng/insect) assuming mosquitoes in each cohort weighed $2.85 \mathrm{mg} / \mathrm{mosquito}$ (average of five cohorts of mosquitoes). The theoretical $\mathrm{LD}_{25}$ produced $14 \pm 1.9 \%$ mortality at $24 \mathrm{~h}$ when averaged across all replicates. The range of average mortality for all cohorts (groups of three or more replicates associated with selected plant essential oils within each group) was 6.6-22\% mortality. As mortality produced by the theoretical dose was lower than expected (i.e., below 25\%), we calculated the co-toxicity factors using the actual percentage mortality produced by natural pyrethrins within each cohort to avoid cohort biases. 
Of the various oils, some produced synergism when applied with natural pyrethrins at $2 \mu \mathrm{g} /$ insect, both of knockdown and mortality (Table 1). Cedarwood (Virginian), dillseed, fir needle oil, fennel, and parsley all produced knockdown co-toxicity factors greater than 20. In this assessment, fir needle oil performed the best with a knockdown co-toxicity factor of 77.6. This response was largely driven by the lack of knockdown produced by fir needle oil and the relatively high increase in knockdown for the mixture $(53.3 \pm 18.6 \%)$. Many other oils increased the knockdown effects of natural pyrethrins, but these were essentially additive, producing co-toxicity factors between -20 and 20 (Table 1). A number of plant essential oils also antagonized knockdown at $1 \mathrm{~h}$. PBO antagonized knockdown with only $10 \pm 3.7 \%$ knockdown observed in combinations of PBO and natural pyrethrins, whereas $47 \%$ knockdown was observed for natural pyrethrins alone. Of the oils, balsam (Copaiba), cade, Canadian balsam fir, dillweed, and ginger root all antagonized the quick immobilizing character of natural pyrethrins at $1 \mathrm{~h}$, with co-toxicity factors less than -20 . Of these, Canadian balsam fir was the most antagonistic (co-toxicity factor $=-63.6$ ). At the screening concentration of $2 \mu \mathrm{g} /$ insect, numerous oils/agents synergized mortality. $\mathrm{PBO}$, the commercial synergist standard used in this study, provided a high degree of synergism with a co-toxicity factor of 71 (Table 1). Amyris, balsam (Copaiba), cedarwood (Texas), cedarwood (Virginian), dillseed, fennel, fir needle oil, and nutmeg E.I. all produced synergism with co-toxicity factors greater than 20. Of these, nutmeg E.I. produced the largest co-toxicity factor (300). The other oils produced additive increases in mortality at $24 \mathrm{~h}$, with the exception of cade, cardamom, cypress, dillweed, galbanum, and ginger root, which produced antagonistic co-toxicity factors (Table 1).

At the $10 \mu \mathrm{g} /$ insect screening concentration, a number of oils synergized the $1 \mathrm{~h}$ knockdown and $24 \mathrm{~h}$ mortality produced by natural pyrethrins (Table 2). Cade, cardamom, cedarwood (Virginian), cypress, dillweed, fir needle, and guaiacwood oils synergized the knockdown of natural pyrethrins at $1 \mathrm{~h}$, with fir needle oil being the most successful. Other oils either additively increased or antagonized $1 \mathrm{~h}$ knockdown. PBO strongly antagonized $1 \mathrm{~h}$ knockdown by natural pyrethrins at the $10 \mu \mathrm{g} /$ insect concentration with a co-toxicity factor of -115 , which was the most negative co-toxicity factor observed in this study. Among the oils, Amyris, balsam (Copaiba), balsam (Peru), Canadian balsam fir, cedarwood (Texas), and galbanum antagonized natural pyrethrins $1 \mathrm{~h}$ knockdown, whereas cedarleaf, dillseed, fennel, ginger root, nutmeg E.I., and parsley all additively increased $1 \mathrm{~h}$ knockdown of natural pyrethrins (Table 2). Many oils synergized natural pyrethrins mortality at $24 \mathrm{~h}$ at the $10 \mu \mathrm{g} /$ insect concentration, whereas PBO did not. PBO instead produced high mortality when applied alone and the improvement of the combined mixture was minimal. Among the synergistic oils, Amyris, balsam (Copaiba), cardamom, cedarleaf, cedarwood (Texas), cedarwood (Virginian), dillseed, dillweed, fennel, ginger root, nutmeg E.I., and parsley, it was found that cardamom was the most active with a co-toxicity factor of 200. The remaining oils, with the exception of Canadian balsam fir and galbanum, increased the $24 \mathrm{~h}$ mortality of natural pyrethrins by an additive extent. Both Canadian balsam fir and galbanum antagonized the toxicity of natural pyrethrins at this concentration. Overall, the results in Tables 1 and 2 show that the synergistic potential of plant essential oils and $\mathrm{PBO}$ is concentration dependent.

To assess the utility and accuracy of the co-toxicity factor metric, we screened a number of plant essential oils and PBO (applied at a sublethal dose of $2 \mu \mathrm{g} /$ insect) with variable concentrations of natural pyrethrins. The $\mathrm{LD}_{50}$ values for natural pyrethrins in these experiments were then compared to the original $\mathrm{LD}_{50}$ of natural pyrethrins to obtain a synergism ratio (Table 3). Of the oils screened in these follow-up studies, Amyris oil + natural pyrethrins produced the lowest $\mathrm{LD}_{50}$ value $(0.21 \mathrm{ng} / \mathrm{mg}$ mosquito $)$ and the highest synergism ratio (7.3). Cedarwood (Texas) also produced significant synergism, but the synergism ratio for this formulation was 4, very similar to that produced by PBO (5.1). The other cedarwood oil, Virginian, also produced significant synergism with a synergism ratio of 3.6. Interestingly, both fir needle oil and citronella oil produced low levels of toxicity synergism, but these were not significant as indicated by $t$-test; $p=0.59$ for fir needle oil 
and $p=0.74$ for citronella. Slope values for natural pyrethrins were relatively unchanged by combined application with these plant essential oils.

Table 3. Dose-response statistics for natural pyrethrins applied alone and in combination with select candidate synergists and their respective synergist ratios.

\begin{tabular}{|c|c|c|c|c|}
\hline Treatment & $\mathbf{N}$ & $\begin{array}{c}\mathrm{LD}_{50} \mathrm{ng} / \mathrm{mg} \text { Insect } \\
(95 \% \mathrm{CI})\end{array}$ & Slope (SE) & Synergism Ratio * \\
\hline Natural pyrethrins (NP) & 290 & $1.53(1.0-3.3)$ & $1.5(0.3)$ & - \\
\hline $\mathrm{NP}+\mathrm{PBO}$ & 210 & $0.3(0.19-0.44)$ & $2.0(0.53)$ & $5.1^{*}$ \\
\hline $\mathrm{NP}+$ citronella & 150 & $1.13(0.7-5.2)$ & $1.7(0.49)$ & 1.4 \\
\hline $\mathrm{NP}+$ Amyris & 150 & $0.21(0.13-0.3)$ & $2.0(0.3)$ & $7.3^{*}$ \\
\hline NP + Cedarwood (Virginian) & 150 & $0.43(0.25-0.77)$ & $1.6(0.49)$ & $3.6^{*}$ \\
\hline NP + Cedarwood (Texas) & 150 & $0.38(0.26-0.57)$ & $1.9(0.36)$ & $4^{*}$ \\
\hline $\mathrm{NP}+$ fir needle oil & 200 & $0.85(0.6-1.2)$ & $2.2(0.38)$ & 1.8 \\
\hline
\end{tabular}

* denotes statistically significant percentage from the control (NP alone) via lack of overlap in $95 \%$ confidence intervals.

\section{Discussion}

Twenty plant essential oils were screened in combination with natural pyrethrins and knockdown at $1 \mathrm{~h}$ and mortality at $24 \mathrm{~h}$ were determined. Many of the oils used in this study have not been screened previously in combination with natural pyrethrins and/or have not been assessed as synergists on Aedes aegypti female mosquitoes. Moreover, assessing enhancement of both knockdown and mortality are important considerations in the characterization of novel public health pest control formulations, as both effects may lead to the prevention of host feeding. Norris et al. [12] proposed that knockdown of intoxicated mosquitoes may lead to higher levels of mortality over time in the field, due to exposure to fungal pathogens, desiccation or starvation through the inability to feed, and increased predation. The present study demonstrated that many plant essential oils not only improve the mortality produced by natural pyrethrins at $24 \mathrm{~h}$, but also improve their speed-of-action.

In order to characterize the synergistic potential of plant essential oils, we first screened them alone to better understand their toxicological contributions in our mixtures. A wide range of toxicities were observed, with balsam (Peru) producing the most significant knockdown at $1 \mathrm{~h}$ at the $10 \mu \mathrm{g} /$ insect concentration. Seo et al. [18] demonstrated that balsam (Peru) is predominantly composed of benzyl benzoate and benzyl cinnamate. These constituents may be useful leads for future insect control formulations, either as natural insecticides or agents that improve the knockdown effects of currently available insecticide formulations. In addition, a significant amount of recovery was observed in mosquitoes treated with this oil (73.3\% knockdown at $1 \mathrm{~h}$ and $26.7 \%$ mortality at $24 \mathrm{~h}$ ), indicating that metabolic processes probably detoxified the constituents within balsam (Peru) oil. Therefore, additional synergists such as PBO or S,S,S-tributylphosphorotrithioate (DEF) should increase the $24 \mathrm{~h}$ toxicity of this oil [19]. Guaiacwood oil and Canadian balsam fir were the most toxic at $24 \mathrm{~h}$, indicating their potential as natural insecticides. Norris et al. [6] demonstrated that guaiacwood oil was predominantly composed of guaiol along with the minor constituent sesquiterpenoids, bulnesol, and bulnesene. Canadian balsam fir is predominantly composed of $\alpha$-pinene, $\beta$-pinene, and phellandrene, any of which may be responsible for its toxicity [20]. Further work is needed to characterize the biological activity of these oils and assess the contribution of each individual constituent towards overall toxicity.

Formulation additives can significantly augment the speed-of-action of select insecticides; therefore, understanding their contribution to speed-of-action is an important consideration, whether additive or synergistic [21]. Five oils synergized $1 \mathrm{hr}$ knockdown at the $2 \mu \mathrm{g}$ dose and six the knockdown observed at the $10 \mu \mathrm{g}$ dose. These findings warrant future exploration as there may be agents within these oils that significantly potentiate the effects of natural pyrethrins directly on the insect nervous system or facilitate the penetra- 
tion of natural pyrethrins across the cuticle. Screening the individual constituents from these oils directly on the nervous system in combination with pyrethroids will identify constituents acting via this mechanism. Moreover, if these oils increase insecticide penetration, it would be valuable to better understand the physicochemical factors underlying these activities. Increased penetration may be facilitated via improved passive diffusion across the cuticle (as in the case of calcofluor [22,23]) or through the inhibition of drug efflux pumps, similar to the mechanism of verapamil, an ATP-binding cassette (ABC) transporter inhibitor [24].

In contrast to the generally positive effects of essential oils on knockdown by natural pyrethrins, $\mathrm{PBO}$ significantly reduced knockdown by this natural insecticide. Norris et al. [10] showed previously that PBO at both 2 and $10 \mu \mathrm{g} / \mathrm{mosquito} \mathrm{could} \mathrm{significantly}$ decrease the knockdown produced by select pyrethroids at $1 \mathrm{~h}$ post-application, and Kasai et al. [17] showed that $1 \mathrm{hr}$ pretreatment with PBO significantly decreased the penetration rate of $\left[{ }^{14} \mathrm{C}\right]$-permethrin into Aedes aegypti females. These findings advise against combining diverse formulation additives simply due to their independent activity. Our study corroborated the earlier findings that PBO significantly slowed the immobilization produced by natural pyrethrins in both the $2 \mu \mathrm{g}$ and $10 \mu \mathrm{g}$ /insect applications.

Synergism of lethality was observed using the co-toxicity method, identifying oils that were synergistic with natural pyrethrins at the low dose application level $(2 \mu \mathrm{g} / \mathrm{insect})$ but not synergistic at the high dose level $(10 \mu \mathrm{g} /$ insect $)$, oils that were synergistic at only the high dose level, those synergistic at both doses, and some that were not synergistic at either dose. This variety of responses was also true for antagonism. These findings demonstrate that synergist concentration must be an important consideration in the development of novel insecticidal mixtures. Unexpectedly, some oils and PBO were synergistic only at the low dose, but not at the high dose, which may result from sequestration of pyrethrins at the cuticular boundary. Moreover, it is possible that at the high dose, excess oil/ PBO did not fully penetrate the insect cuticle. Of these oils, nutmeg E.I. produced the largest co-toxicity factor (Table 1), perhaps due to the constituents safrole and myristicin, natural compounds that are structurally similar to PBO [25] and contain an identical methylenedioxyphenyl moiety [26]. Yang et al. 2015 demonstrated that myristicin was capable of inactivating human CYP1A2 (cytochrome P450 monooxygenase) via mechanism-based inhibition [27], similar to the action of PBO [26,27]. At $10 \mu \mathrm{g} /$ insect, cardamom produced the highest co-toxicity factor (200) seen at this dose. This oil is predominantly composed of complex mixtures of oxygenated monoterpenoids [28]. Further work will be needed to separate these constituents to ascertain their specific bioactivity and mechanisms of action. While this study identified a number of novel synergistic plant essential oils, some apparent differences from other studies were noted. For example, Tak et al. [8] showed that $10 \mu \mathrm{g} /$ female doses of cedarwood, dill, and fennel oils applied in combination with permethrin did not produce statistically significant mortality greater than permethrin alone, whereas cedarwoods, dillweed and dillseed, and fennel oils synergized natural pyrethrins at the specific doses studied here. The greater potential of plant essential oils to increase the toxicity of natural pyrethrins vs. permethrin may result from greater susceptibility of natural pyrethrins to metabolic degradation than permethrin. If this is the case, inhibition of metabolic processes by plant essential oils may more significantly increase the toxicity of natural pyrethrins than permethrin. Norris et al. put forth a similar justification after finding type I pyrethroids were more strongly synergized by plant essential oils than type II pyrethroids [12].

To further evaluate the co-toxicity factor method, we selected a number of plant essential oils that produced co-toxicity factors greater than 20 (and those that produced co-toxicity factors between -20 and 20) to assess whether this method translated well to the established $\mathrm{LD}_{50}$ ratio method of identifying synergism. If the co-toxicity factor method was meaningful and scientifically sound, it should translate well to another metric commonly utilized to measure synergism in the literature $[16,29,30]$. In these studies, oils that produced co-toxicity factors greater than 20 also produced significant synergism ratios, 
such as Amyris, cedarwood (Virginian), and cedarwood (Texas). Moreover, the two oils that did not produce additive co-toxicity factors (i.e., between -20 and 20), citronella and fir needle oil, did not produce statistically significant synergism ratios. Correlation between traditional synergism ratios and co-toxicity factors at the $2 \mu \mathrm{g} /$ insect level was quite strong (Pearson Correlation $r=0.94$ ) (Figure 1). For example, Amyris produced the largest synergism ratio and the largest co-toxicity factor. Direct correlation was less pronounced when comparing the synergism ratios obtained using $2 \mu \mathrm{g} /$ insect $+\mathrm{NP}$ with the co-toxicity factors obtained using $10 \mu \mathrm{g} /$ insect of oil (Pearson Correlation $\mathrm{r}=0.64$ ). It is possible that the slope values of combined mixtures may directly affect the degree of co-toxicity factors observed at low or high potency screening concentrations, in addition to any number of toxicokinetic/dynamic factors. Differences in the ability of plant essential oils to inhibit metabolic processes or aid/hinder penetration of natural pyrethrins may also differ at each respective dose applied (2 or $10 \mu \mathrm{g})$. More work needs to be performed to comprehensively evaluate the strengths and weaknesses of this method, but our study supports the throughput and merit of co-toxicity metric analysis.
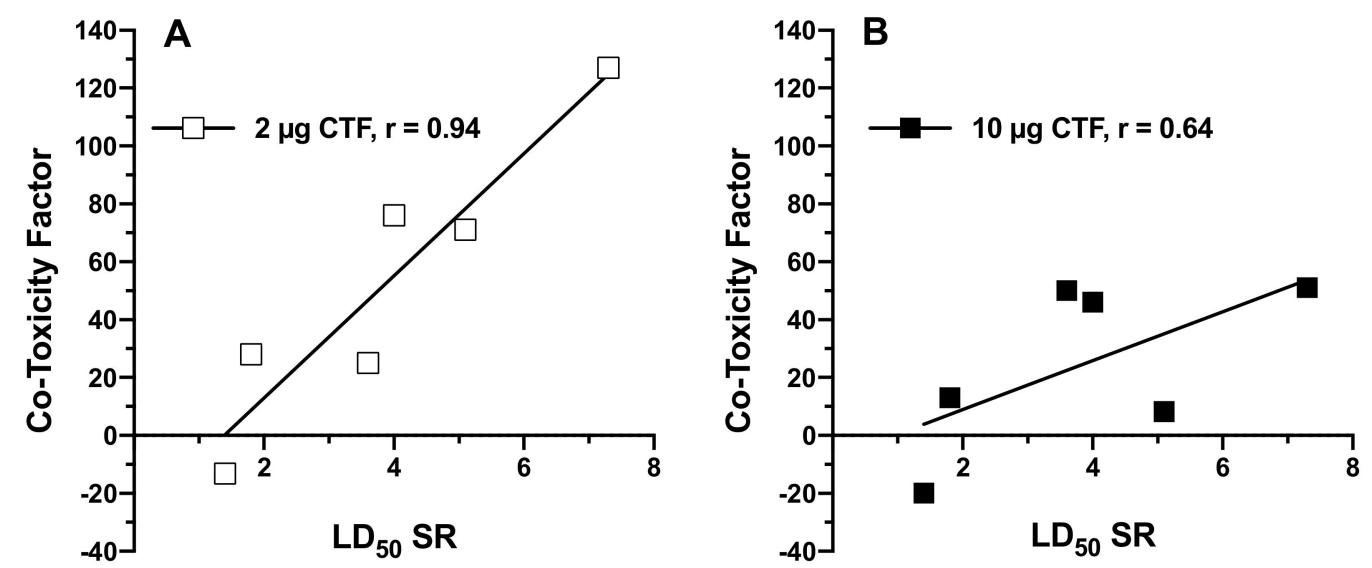

Figure 1. Synergism ratios of $\mathrm{LD}_{50}$ values (SR) plotted against co-toxicity factors (CTF) obtained at (A) $2 \mu \mathrm{g} /$ insect and (B) $10 \mu \mathrm{g} /$ insect, along with linear regression analysis. Strong linear correlation value was observed for the $2 \mu \mathrm{g} / \mathrm{insect}$ (Pearson's correlation coefficient $\mathrm{r}=0.94$ ), whereas at $10 \mu \mathrm{g}$ /insect moderate linear correlation was observed (Pearson's correlation coefficient $\mathrm{r}=0.64$ ).

Insecticide synergists improve the efficacy of various synthetic and natural insecticides, potentially allowing them to overcome insecticide resistance in the field [31]. Future work should be done to assess how these affect insecticide resistance to various insecticidal classes. Previous studies have shown that specific plant essential oils increase the toxicity of permethrin and deltamethrin on both pyrethroid-resistant and pyrethroidsusceptible strains of Ae. aegypti and Anopheles gambiae [13,14]. As many of the essential oils screened in this exploration were not screened against insecticide-resistant strains, it is imperative to elucidate their potential as resistance-breaking insecticide additives. Moreover, Kumar et al. [32] demonstrated that mosquito strains selected with deltamethrin over 40 generations were $60 \%$ less resistant when selected against combinations of PBO and deltamethrin (compared to deltamethrin alone). This suggests synergists may not only play a role after the development of insecticide resistance, but may serve to slow its development, also.

\section{Conclusions}

This study demonstrates the potential of a set of plant essential oils to selectively enhance or antagonize natural pyrethrins when both are applied in combination. Not only did some of these oils synergize natural pyrethrins-based mortality at $24 \mathrm{~h}$, they also increased its ability to immobilize insects shortly after exposure (knockdown at $1 \mathrm{~h}$ ). However, not all oils produced synergism, with many producing antagonisms of natural 
pyrethrins toxicity. In fact, synergism and/or antagonism was highly dose dependent. This study demonstrates the utility of select plant essential oils as leads for the development of future insecticide synergists. Many of the oils identified as synergists of either knockdown or lethality have not been studied before as synergists against Ae. aegypti mosquitoes. Further, the dose dependence of synergistic/antagonistic interactions demonstrates that the dose of individual agents in insecticidal mixtures should be carefully considered.

Author Contributions: Conceptualization, E.J.N. and J.R.B.; Methodology, E.J.N. and J.R.B.; Validation, E.J.N. and J.R.B.; Formal Analysis, E.J.N. and J.R.B.; Investigation, E.J.N. and J.R.B.; Resources, J.R.B.; Data Curation, E.J.N.; Writing-Original Draft Preparation, E.J.N.; Writing-Review and editing, E.J.N. and J.R.B.; Visualization, E.J.N. and J.R.B.; Supervision, J.R.B.; Project Administration, E.J.N. and J.R.B.; Funding Acquisition, J.R.B. All authors have read and agreed to the published version of the manuscript.

Funding: This research was supported in part by CDC (https: / www.cdc.gov /) grant 1U01CK000510: Southeastern Regional Center of Excellence in Vector-Borne Diseases: The Gateway Program.

Institutional Review Board Statement: Not applicable.

Acknowledgments: The CDC had no role in the design of the study; the collection, analysis, and interpretation of data; or in writing the manuscript. We would also like to thank Dan Kline for supplying Aedes aegypti mosquitoes for this study. This research was also supported by the U.S. Department of Agriculture (USDA) - Agricultural Research Service. The USDA is an equal opportunity provider and employer.

Conflicts of Interest: The authors declare no conflict of interest.

\section{References}

1. Isman, M.B.; Grieneisen, M.L. Botanical insecticide research: Many publications, limited useful data. Trends Plant. Sci. 2014, 19, 140-145. [CrossRef]

2. Isman, M.B. Plant essential oils for pest and disease management. Crop. Prot. 2000, 19, 603-608. [CrossRef]

3. Isman, M.B. A renaissance for botanical insecticides? Pest. Manag. Sci. 2015, 71, 1587-1590. [CrossRef]

4. Miresmailli, S.; Isman, M.B. Botanical insecticides inspired by plant-herbivore chemical interactions. Trends Plant. Sci. 2014, 19, 29-35. [CrossRef] [PubMed]

5. Qualls, W.A.; Xue, R.D.; Farooq, M.; Peper, S.T.; Aryaprema, V.; Blore, K.; Weaver, R.; Autry, D.; Talbalaghi, A.; Kenar, J.; et al. Evaluation of Lotions of Botanical-Based Repellents Against Aedes aegypti (Diptera: Culicidae). J. Med. Entomol. 2020. [CrossRef]

6. Norris, E.J.; Gross, A.D.; Dunphy, B.M.; Bessette, S.; Bartholomay, L.; Coats, J.R. Comparison of the Insecticidal Characteristics of Commercially Available Plant Essential Oils Against Aedes aegypti and Anopheles gambiae (Diptera: Culicidae). J. Med. Entomol. 2015, 52, 993-1002. [CrossRef] [PubMed]

7. Tong, F.; Bloomquist, J.R. Plant essential oils affect the toxicities of carbaryl and permethrin against Aedes aegypti (Diptera: Culicidae). J. Med. Entomol. 2013, 50, 826-832. [CrossRef]

8. Tak, J.H.; Coquerel, Q.R.R.; Tsikolia, M.; Bernier, U.R.; Linthicum, K.; Bloomquist, J.R. Screening for Enhancement of Permethrin Toxicity by Plant Essential Oils Against Adult Females of the Yellow Fever Mosquito (Diptera: Culicidae). J. Med. Entomol. 2020, 57, 1149-1156. [CrossRef]

9. Gross, A.D.; Norris, E.J.; Kimber, M.J.; Bartholomay, L.C.; Coats, J.R. Essential oils enhance the toxicity of permethrin against Aedes aegypti and Anopheles gambiae. Med. Vet. Entomol. 2017, 31, 55-62. [CrossRef] [PubMed]

10. Mansour, N.A.; Eldefrawi, M.E.; Toppozoda, A.; Zeid, M. Toxicological studies on the Egyptian cotton leafworm, Prodenia litura. VI. Potentiation and antagonism of organophosphorus and carbamate insecticides. Econ. Entomol. 1966, 59, 307-311. [CrossRef]

11. Norris, E.J.; Archevald-Cansobre, M.; Gross, A.D.; Bartholomay, L.C.; Coats, J.R. Rapid immobilization of adult Aedes aegypti by plant essential oils at sublethal concentrations. Am. Mosq. Control. Assoc. 2018, 34, 210-216. [CrossRef]

12. Norris, E.J.; Gross, A.D.; Bartholomay, L.C.; Coats, J.R. Plant essential oils synergize various pyrethroid insecticides and antagonize malathion in Aedes aegypti. Med. Vet. Entomol. 2019, 33, 453-466. [CrossRef]

13. Norris, E.J.; Johnson, J.B.; Gross, A.D.; Bartholomay, L.C.; Coats, J.R. Plant Essential Oils Enhance Diverse Pyrethroids against Multiple Strains of Mosquitoes and Inhibit Detoxification Enzyme Processes. Insects 2018, 9, 132. [CrossRef] [PubMed]

14. Chansang, A.; Champakaew, D.; Junkum, A.; Jitpakdi, A.; Amornlerdpison, D.; Aldred, A.K.; Riyong, D.; Wannasan, A.; Intirach, J.; Muangmoon, R.; et al. Synergy in the adulticidal efficacy of essential oils for the improvement of permethrin toxicity against Aedes aegypti L. (Diptera: Culicidae). Parasites Vectors 2018, 11, 417. [CrossRef] [PubMed]

15. Pridgeon, J.W.; Meepagala, K.M.; Becnel, J.J.; Clark, G.G.; Pereira, R.M.; Linthicum, K.J. Structure-activity relationships of 33 piperidines as toxicants against female adults of Aedes aegypti (Diptera: Culicidae). J. Med Entomol. 2007, 44, 263-269. [CrossRef] 
16. Jiang, S.; Yang, L.; Bloomquist, J.R. High-throughput screening method for evaluating spatial repellency and vapour toxicity to mosquitoes. Med. Vet. Entomol. 2019, 33, 388-396. [CrossRef]

17. Finney, D.J. Probit Analysis: A Statistical Treatment of the Sigmoid Response Curve, 2nd ed.; Cambridge University Press: Cambridge, UK, 1952.

18. Seo, S.M.; Park, H.M.; Park, I.K. Larvicidal activity of ajowan (Trachyspermum ammi) and Peru balsam (Myroxylon pereira) oils and blends of their constituents against mosquito, Aedes aegypti, acute toxicity on water flea, Daphnia magna, and aqueous residue. J. Agric. Food Chem. 2012, 60, 5909-5914. [CrossRef] [PubMed]

19. Sanei Dehkordi, A.; Salim Abadi, Y.; Nasirian, H.; Hazratian, T.; Gorouhi, M.A.; Yousefi, S.; Paksa, A. Synergists action of piperonyl butoxide and S,S,S-tributyl phosphorotrithioate on toxicity of carbamate insecticides against Blattella germanica. Asian Pac. J. Trop. Med. 2017, 10, 981-986. [CrossRef] [PubMed]

20. Ross, J.; Gagnon, H.; Girard, D.; Hachey, J.-M. Chemical Composition of the Bark Oil of Balsam FirAbies balsamea(L.) Mill. J. Essent. Oil Res. 1996, 8, 343-346. [CrossRef]

21. Hall, F.R. Pesticide Formulations and Other Parameters Affecting Dose Transfer. In Pesticide Formulations; American Chemical Society: Washington, DC, USA, 1988; pp. 260-278. [CrossRef]

22. Wang, P.; Granados, R.R. Calcofluor disrupts the midgut defense system in insects. Insect Biochem. Mol. Biol. 2000, 30, 135-143. [CrossRef]

23. Leetachewa, S.; Khomkhum, N.; Sakdee, S.; Wang, P.; Moonsom, S. Enhancement of insect susceptibility and larvicidal efficacy of Cry4Ba toxin by calcofluor. Parasites Vectors 2018, 11, 515. [CrossRef]

24. Epis, S.; Poretta, D.; Mastrantonio, V.; Comandatore, F.; Sassera, D.; Rossi, P.; Cafarchia, C.; Otranto, D.; Favia, G.; Genchi, C.; et al. $\mathrm{ABC}$ transporters are involved in defense against permethrin insecticide in the malaria vector Anopheles stephensi. Parasites Vectors 2014, 7, 349-356. [CrossRef]

25. Kapoor, I.P.S.; Singh, B.; Singh, G.; De Heluani, C.S.; De Lampasona, M.P.; Catalan, C.A.N. Chemical Composition and Antioxidant Activity of Essential Oil and Oleoresins of Nutmeg (Myristica fragrans Houtt.) Fruits. Int. J. Food Properties 2013, 16, 1059-1070. [CrossRef]

26. Philpot, R.M.; Hodgson, E. The production and modification of cytochrome P-450 difference spectra by in vivo administration of methylenedioxyphenyl compounds. Chem. Biol. Interact. 1971, 4, 185-194. [CrossRef]

27. Yang, A.H.; He, X.; Chen, J.X.; He, L.N.; Jin, C.H.; Wang, L.L.; Zhang, F.L.; An, L.J. Identification and characterization of reactive metabolites in myristicin-mediated mechanism-based inhibition of CYP1A2. Chem. Biol. Interact. 2015, 237, 133-140. [CrossRef]

28. Noumi, E.; Snoussi, M.; Alreshidi, M.M.; Rekha, P.D.; Saptami, K.; Caputo, L.; De Martino, L.; Souza, L.F.; Msaada, K.; Mancini, E.; et al. Chemical and Biological Evaluation of Essential Oils from Cardamom Species. Molecules 2018, 23. [CrossRef] [PubMed]

29. Yang, L.; Richoux, G.M.; Norris, E.J.; Cuba, I.; Jiang, S.; Coquerel, Q.; Demares, F.; Linthicum, K.J.; Bloomquist, J.R. PyrethroidDerived Acids and Alcohols: Bioactivity and Synergistic Effects on Mosquito Repellency and Toxicity. J. Agric. Food Chem. 2020, 68, 3061-3070. [CrossRef] [PubMed]

30. Yang, L.; Norris, E.J.; Jiang, S.; Bernier, U.R.; Linthicum, K.J.; Bloomquist, J.R. Reduced effectiveness of repellents in a pyrethroidresistant strain of Aedes aegypti (Diptera: Culicidae) and its correlation with olfactory sensitivity. Pest. Manag. Sci. 2020, 76, 118-124. [CrossRef]

31. Casida, J.E. Mixed-function oxidase involvement in the biochemistry of insecticide synergists. J. Agric. Food Chem. 1970, 18, 753-772. [CrossRef]

32. Kumar, S.; Thomas, A.; Sahgal, A.; Verma, A.; Samuel, T.; Pillai, M.K. Effect of the synergist, piperonyl butoxide, on the development of deltamethrin resistance in yellow fever mosquito, Aedes aegypti L. (Diptera: Culicidae). Arch. Insect Biochem. Physiol. 2002, 50, 1-8. [CrossRef] 